\title{
Anomalies: The Endowment Effect, Loss Aversion, and Status Quo Bias
}

\author{
Daniel Kahneman; Jack L. Knetsch; Richard H. Thaler
}

The Journal of Economic Perspectives, Vol. 5, No. 1. (Winter, 1991), pp. 193-206.

Stable URL:

http://links.jstor.org/sici?sici=0895-3309\%28199124\%295\%3A1\%3C193\%3AATEELA\%3E2.0.CO\%3B2-V

The Journal of Economic Perspectives is currently published by American Economic Association.

Your use of the JSTOR archive indicates your acceptance of JSTOR's Terms and Conditions of Use, available at

http://www.jstor.org/about/terms.html. JSTOR's Terms and Conditions of Use provides, in part, that unless you have obtained prior permission, you may not download an entire issue of a journal or multiple copies of articles, and you may use content in the JSTOR archive only for your personal, non-commercial use.

Please contact the publisher regarding any further use of this work. Publisher contact information may be obtained at http://www.jstor.org/journals/aea.html.

Each copy of any part of a JSTOR transmission must contain the same copyright notice that appears on the screen or printed page of such transmission.

The JSTOR Archive is a trusted digital repository providing for long-term preservation and access to leading academic journals and scholarly literature from around the world. The Archive is supported by libraries, scholarly societies, publishers, and foundations. It is an initiative of JSTOR, a not-for-profit organization with a mission to help the scholarly community take advantage of advances in technology. For more information regarding JSTOR, please contact support@jstor.org. 


\title{
Anomalies \\ The Endowment Effect, Loss Aversion, and Status Quo Bias
}

\author{
Daniel Kahneman, Jack L. Knetsch, \\ and Richard H. Thaler
}

Economics can be distinguished from other social sciences by the belief that most (all?) behavior can be explained by assuming that agents have stable, well-defined preferences and make rational choices consistent with those preferences in markets that (eventually) clear. An empirical result qualifies as an anomaly if it is difficult to "rationalize," or if implausible assumptions are necessary to explain it within the paradigm. This column presents a series of such anomalies. Readers are invited to suggest topics for future columns by sending a note with some reference to (or better yet copies of) the relevant research. Comments on anomalies printed here are also welcome. The address is: Richard Thaler, c/o Journal of Economic Perspectives, Johnson Graduate School of Management, Malott Hall, Cornell University, Ithaca, NY 14853.

After this issue, the "Anomalies" column will no longer appear in every issue and instead will appear occasionally, when a pressing anomaly crosses Dick Thaler's desk. However, suggestions for new columns and comments on old ones are still welcome. Thaler would like to quash one rumor before it gets started, namely that he is cutting back because he has run out of anomalies. $A u$ contraire, it is the dilemma of choosing which juicy anomaly to discuss that takes so much time.

Daniel Kahneman is Professor of Psychology, University of California, Berkeley, California. Jack L. Knetsch is Professor of Economics and Natural Resources Management, Simon Fraser University, Burnaby, British Columbia, Canada. Richard H. Thaler is Henrietta Johnson Louis Professor of Economics, Johnson School of Management, Cornell University, Ithaca, New York. 


\section{Introduction}

A wine-loving economist we know purchased some nice Bordeaux wines years ago at low prices. The wines have greatly appreciated in value, so that a bottle that cost only $\$ 10$ when purchased would now fetch $\$ 200$ at auction. This economist now drinks some of this wine occasionally, but would neither be willing to sell the wine at the auction price nor buy an additional bottle at that price.

Thaler (1980) called this pattern-the fact that people often demand much more to give up an object than they would be willing to pay to acquire it - the endowment effect. The example also illustrates what Samuelson and Zeckhauser (1988) call a status quo bias, a preference for the current state that biases the economist against both buying and selling his wine. These anomalies are a manifestation of an asymmetry of value that Kahneman and Tversky (1984) call loss aversion - the disutility of giving up an object is greater that the utility associated with acquiring it. This column documents the evidence supporting endowment effects and status quo biases, and discusses their relation to loss aversion.

\section{The Endowment Effect}

An early laboratory demonstration of the endowment effect was offered by Knetsch and Sinden (1984). The participants in this study were endowed with either a lottery ticket or with $\$ 2.00$. Some time later, each subject was offered an opportunity to trade the lottery ticket for the money, or vice versa. Very few subjects chose to switch. Those who were given lottery tickets seemed to like them better than those who were given money.

This demonstration and other similar ones (Knetsch, 1989), while striking, did not settle the matter. Some economists felt that the behavior would disappear if subjects were exposed to a market environment with ample learning opportunities. For example, Knez, Smith and Williams (1985) argued that the discrepancy between buying and selling prices might be produced by the thoughtless application of normally sensible bargaining habits, namely understating one's true willingness to pay (WTP) and overstating the minimum acceptable price at which one would sell (willingness to accept or WTA). Coursey, Hovis, and Schultze (1987) reported that the discrepancy between WTP and WTA diminished with experience in a market setting (although it was probably not eliminated, see Knetsch and Sinden, 1987). To clarify the issue, Kahneman, Knetsch, and Thaler (1990) ran a new series of experiments to determine whether the endowment effect survives when subjects face market discipline and have a chance to learn. We will report just two experiments from that series. 
In the first experiment, students in an advanced undergraduate economics class at Cornell University participated in a series of markets. The objects traded in the first three markets were 'induced value tokens.' In such markets all subjects are told how much a token is worth to them, with the amounts varying across subjects. Half the subjects were made owners of tokens, the other half were not. In this way, supply and demand curves for tokens are created. Subjects alternated between the buyer and seller role in the three successive markets, and were assigned a different individual redemption value in each trial. Experimenters collected the forms from all participants after each market period, and immediately calculated and announced the market-clearing price and the number of trades. Three buyers and three sellers were selected at random after each of the induced markets and were paid off according to the preferences stated on their forms and the market clearing price for that period.

These markets contained no grist for the anomaly mill. On each trial, the market clearing price was exactly equal to the intersection of the induced supply and demand curves, and the volume of trade was within one unit of the predicted quantity. These results demonstrate that the subjects understood the task, and that the market mechanism used did not impose high transactions costs.

Immediately after the three induced value markets, subjects on alternating seats were given Cornell coffee mugs, which sell for $\$ 6.00$ each at the bookstore. The experimenter asked all participants to examine a mug, either their own or their neighbor's. The experimenter then informed the subjects that four markets for mugs would be conducted using the same procedures as the prior induced markets with two exceptions: (1) One of the four market trials would subsequently be selected at random and only the trades made on this trial would be executed. (2) On the binding market trial, all trades would be implemented, unlike the subset implemented in the induced value markets. The initial assignment of buyer and seller roles was maintained for all four trading periods. The clearing price and the number of trades were announced after each period. The market that "counted" was indicated after the fourth period, and transactions were executed immediately-all sellers who had indicated that they would give up their mug at the market clearing price exchanged their mugs for cash, and successful buyers paid this same price and received their mug. This design was used to permit learning to take place over successive trials and yet make each trial potentially binding. The same procedure was then followed for four more successive markets using boxed ball-point pens with a visible bookstore price tag of $\$ 3.98$, which were distributed to the subjects who had been buyers in the mug markets.

What does economic theory predict will happen in these markets for mugs and pens? Since transactions costs have been shown to be insignificant in the induced value markets, and income effects are trivial, a clear prediction is available: When the market clears, the objects will be owned by those subjects who value them most. Call the half of the subjects who like mugs the most 
"mug lovers" and the half who like mugs least "mug haters." Then, since the mugs were assigned at random, on average half of the mug lovers will be given a mug, and half will not. This implies that in the market, half of the mugs should trade, with mug haters selling to mug lovers.

The 50 percent predicted volume of trade did not materialize. There were 22 mugs and pens distributed so the predicted number of trades was 11 . In the four mug markets the number of trades was $4,1,2$, and 2 respectively. In the pen markets the number of trades was either 4 or 5 . In neither market was there any evidence of a trend over the four trials. The reason for the low volume of trade is revealed by the reservation prices of buyers and sellers. For mugs, the median owner was unwilling to sell for less than $\$ 5.25$, while the median buyer was unwilling to pay more than $\$ 2.25-\$ 2.75$. The market price varied between $\$ 4.25$ and $\$ 4.75$. In the market for pens the ratio of selling to buying prices was also about 2 . The experiment was replicated several times, always with similar results: median selling prices are about twice median buying prices and volume is less than half of that expected.

Another experiment from this series allows us to investigate whether the low volume of trading is produced by a reluctance to buy or a reluctance to sell. In this experiment, 77 students at Simon Fraser University were randomly assigned to three conditions. One group, the Sellers, were given SFU coffee mugs and were asked whether they would be willing to sell the mugs at each of a series of prices ranging from $\$ 0.25$ to $\$ 9.25$. A second group of Buyers were asked whether they would be willing to buy a mug at the same set of prices. The third group, called Choosers, were not given a mug but were asked to choose, for each of the prices, between receiving a mug or that amount of money.

Notice that the Sellers and the Choosers are in objectively identical situations, deciding at each price between the mug and that amount of money. Nevertheless, the Choosers behaved more like Buyers than like Sellers. The median reservation prices were: Sellers, $\$ 7.12$; Choosers, $\$ 3.12$; Buyers, $\$ 2.87$. This suggests that the low volume of trade is produced mainly by owner's reluctance to part with their endowment, rather than by buyers' unwillingness to part with their cash. This experiment also eliminates the trivial income effect present in the first experiment, since the Sellers and Choosers are in the same economic situation.

One of the first lessons in microeconomics is that two indifference curves can never intersect. This result depends on the implicit assumption that indifference curves are reversible. That is, if an individual owns $x$ and is indifferent between keeping it and trading it for $y$, then when owning $y$ the individual should be indifferent about trading it for $x$. If loss aversion is present, however, this reversibility will no longer hold. Knetsch (1990) has demonstrated this point experimentally. One group of subjects received 5 medium priced ball point pens, while another group of subjects received $\$ 4.50$. They were then made a series of offers which they could accept or reject. The offers were designed to identify an indifference curve. For example, someone 


\section{Figure 1}
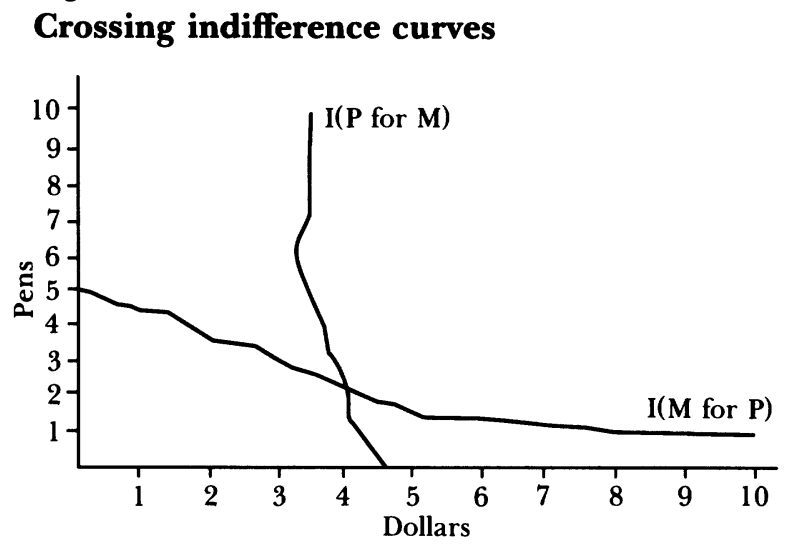

who had been given the pens would be asked if she would give up one of the pens for a dollar. One of the accepted offers (including the original endowment) was selected at random at the end of the experiment to determine the subject's payment. By plotting the line between accepted and rejected offers, Knetsch was able to infer an indifference curve for each subject. Then he plotted the average indifference curve for each of the two groups (those who started with pens and those who started with money). These plots are shown in Figure 1. The curves are quite different: the pens were worth more money to those subjects who started with pens than to those who started with money. As a result, the curves intersect. ${ }^{1}$

What produces these "instant endowment effects"? Do subjects who receive a gift actually value it more than others who do not receive it? A recent study by Loewenstein and Kahneman (1991) investigated this issue. Half the students in a class $(N=63)$ were given pens, the others were given a token redeemable for an unspecified gift. All participants were then asked to rank the attractiveness of six gifts under consideration as prizes in subsequent experiments. Finally, all the subjects were then given a choice between a pen and two chocolate bars. As in previous experiments, there was a pronounced endowment effect. The pen was preferred by 56 percent of those endowed with it, but only 24 percent of the other subjects chose a pen. However, when making the attractiveness ratings, the subjects endowed with pens did not rate them as more attractive. This suggests that the main effect of endowment is not to enhance the appeal of the good one owns, only the pain of giving it up.

\section{Status Quo Bias}

One implication of loss aversion is that individuals have a strong tendency to remain at the status quo, because the disadvantages of leaving it loom larger

\footnotetext{
${ }^{1}$ These curves were obtained from different individuals. Because subjects were randomly assigned to the two endowment groups, however, it is reasonable to attribute crossing indifference curves to the representative individual.
} 
than advantages. Samuelson and Zeckhauser (1988) have demonstrated this effect, which they term the status quo bias. In one experiment, some subjects were given a hypothetical choice task, such as the following, in a 'neutral' version in which no status quo is defined: "You are a serious reader of the financial pages but until recently have had few funds to invest. That is when you inherited a large sum of money from your great-uncle. You are considering different portfolios. Your choices are to invest in: a moderate-risk company, a high risk company, treasury bills, municipal bonds."

Other subjects were presented with the same problem but with one of the options designated as the status quo. In this case, after the same opening sentence the passage continues: “... That is when you inherited a portfolio of cash and securities from your great-uncle. A significant portion of this portfolio is invested in a moderate risk company... (The tax and broker commission consequences of any change are insignificant.)"

Many different scenarios were investigated, all using the same basic experimental design. Aggregating across all the different questions, Samuelson and Zeckhauser are then able to estimate the probability that an option will be selected when it is the status quo or when it is competing as an alternative to the status quo as a function of how often it is selected in the neutral setting. Their results implied that an alternative became significantly more popular when it was designated as the status quo. Also, the advantage of the status quo increases with the number of alternatives.

A test of status quo bias in a field setting was performed by Hartman, Doane, and Woo (forthcoming) using a survey of California electric power consumers. The consumers were asked about their preferences regarding service reliability and rates. They were told that their answers would help determine company policy in the future. The respondents fell into two groups, one with much more reliable service than the other. Each group was asked to state a preference among six combinations of service reliabilities and rates, with one of the combinations designated as the status quo. The results demonstrated a pronounced status quo bias. In the high reliability group, 60.2 percent selected their status quo as their first choice, while only 5.7 percent expressed a preference for the low reliability option currently being experienced by the other group, though it came with a 30 percent reduction in rates. The low reliability group, however, quite liked their status quo, 58.3 percent of them ranking it first. Only 5.8 percent of this group selected the high reliability option at a proposed 30 percent increase in rates. ${ }^{2}$

\footnotetext{
${ }^{2}$ Differences in income and electricity consumption between the two groups were minor and did not appear to significantly influence the results. Could the results be explained by either learning of habituation? That is, might the low reliability group have learned to cope with frequent outages, or found out that candlelight dinners are romantic? This cannot be ruled out, but it should be stressed that no similar explanation can be used for the mug experiments or the surveys conducted by Samuelson and Zeckhauser, so at least some of the effects observed are attributable to a pure status quo bias.
} 
A large-scale experiment on status quo bias is now being conducted (inadvertently) by the states of New Jersey and Pennsylvania. Both states now offer a choice between two types of automobile insurance: a cheaper policy that restricts the right to sue, and a more expensive one that maintains the unrestricted right. Motorists in New Jersey are offered the cheaper policy as the default option, with an opportunity to acquire an unrestricted right to sue at a higher price. Since this option was made available in 1988, 83 percent of the drivers have elected the default option. In Pennsylvania's 1990 law, however, the default option is the expensive policy, with an opportunity to opt for the cheaper kind. The potential effect of this legislative framing manipulation was studied by Hershey, Johnson, Meszaros, and Robinson (1990). They asked two groups to choose between alternative policies. One group was presented with the New Jersey plan while the other was presented with the Pennsylvania plan. Of those subjects offered the New Jersey plan, only 23 percent elected to buy the right to sue whereas 53 percent of the subjects offered the Pennsylvania plan retained that right. On the basis of this research, the authors predict that more Pennsylvanians will elect the right to sue than New Jerseyans. Time will tell.

One final example of a presumed status quo bias comes courtesy of the JEP staff. Among Carl Shapiro's comments on this column was this gem: "You may be interested to know that when the AEA was considering letting members elect to drop one of the three Association journals and get a credit, prominent economists involved in that decision clearly took the view that fewer members would choose to drop a journal if the default was presented as all three journals (rather than the default being 2 journals with an extra charge for getting all three). We're talking economists here."

\section{Loss Aversion}

These observations, and many others, can be explained by a notion of loss aversion. A central conclusion of the study of risky choice has been that such choices are best explained by assuming that the significant carriers of utility are not states of wealth or welfare, but changes relative to a neutral reference point. Another central result is that changes that make things worse (losses) loom larger than improvements or gains. The choice data imply an abrupt change of the slope of the value function at the origin. The existing evidence suggests that the ratio of the slopes of the value function in two domains, for small or moderate gains and losses of money, is about 2:1 (Tversky and Kahneman, 1991). A schematic value function is shown in Figure 2.

The natural extension of this idea to riskless choice is that the attributes of options in trades and other transactions are also evaluated as gains and losses relative to a neutral reference point. The approach is illustrated in Figure 3. Decision makers have a choice between state $A$, where they have more of good 
Figure 2

\section{A typical value function}

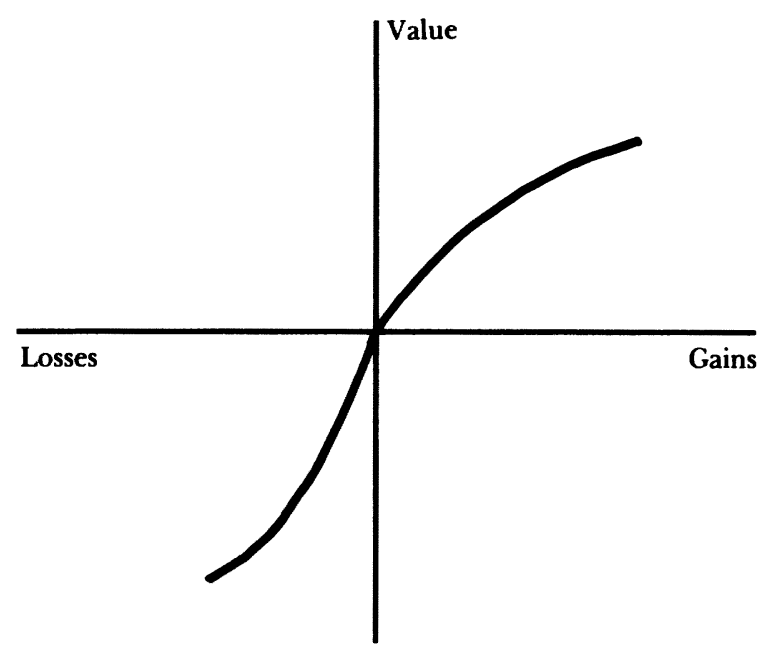

$Y$ and less of good $X$, and state $D$, where they have more of good $X$ and less of good $Y$. Four different reference points are indicated in the Figure. The individual faces a positive choice between two gains if the reference point is $C$, a negative choice between two losses if the reference point is $B$, and two different exchanges if the references are $A$ or $D$, respectively. For example, if good $Y$ is a mug and good $X$ is money, the reference points for the sellers and the choosers in the mugs experiment are $A$ and $C$. Loss aversion implies that the difference between the states of having a mug and not having one is larger from $A$ than from $C$, which explains the different monetary values that subjects attach to the mug in these conditions. ${ }^{3}$ For a formal treatment that generalizes consumer theory by introducing the notions of reference and loss aversion, see Tversky and Kahneman (1991).

In general, a given difference between two options will have greater impact if it is viewed as a difference between two disadvantages than if it is viewed as a difference between two advantages. The status quo bias is a natural consequence of this asymmetry: the disadvantages of a change loom larger than its advantages. However, the differential weighting of advantages and disadvantages can be demonstrated even when the retention of the status quo is not an option. For an example, consider the following question (from Tversky and Kahneman, 1991):

Imagine that as part of your professional training you were assigned to a part-time job. The training is now ending and you must look for employ-

\footnotetext{
${ }^{3}$ Loss aversion does not affect all transactions. In a normal commercial transaction, the seller does not suffer a loss when trading a good. Furthermore, the evidence indicates that buyers do not value the money spent on normal purchases as a loss, so long as the price of the good is not thought to be unusually high. Loss aversion is expected to primarily affect owners of goods that had been bought for use rather than for eventual resale.
} 
Figure 3

Multiple reference points for the choice between $A$ and $D$

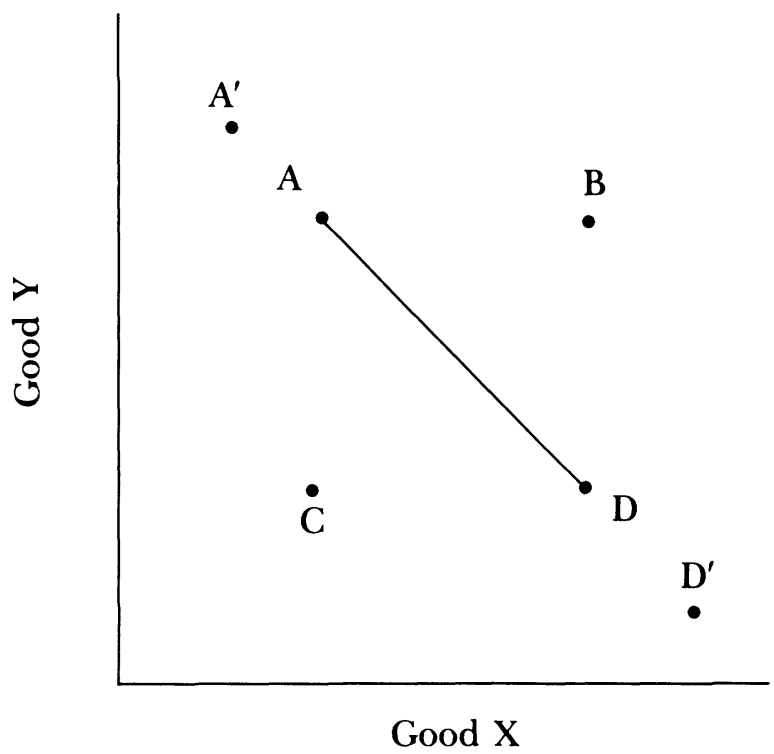

ment. You consider two possibilities. They are like your training job in most respects except for the amount of social contact and the convenience of commuting to and from work. To compare the two jobs to each other and to the present one you have made up the following table:

\begin{tabular}{|c|c|c|}
\hline Job & Contact with others & Commute Time \\
\hline Present jo & isolated for long stretches & $10 \mathrm{~min}$. \\
\hline Job $A$ & limited contact with others & $20 \mathrm{~min}$. \\
\hline Job $D$ & moderately sociable & $60 \mathrm{~min}$. \\
\hline
\end{tabular}

The options $A$ and $D$ are evaluated from a reference job which is better on commute time and worse on personal contact (a point like $A^{\prime}$ in Figure 3). Another version of the problem presented the same options, but the reference job involved "much pleasant social interaction and 80 minutes of daily commuting time," which corresponds to the point $D^{\prime}$. The proportion of subjects choosing job $A$ was 70 percent in the first version, 33 percent in the second. Subjects are more sensitive to the dimension in which they are losing relative to their reference point.

Some asymmetries between buying and selling prices are much too large to be explained by garden-variety loss aversion. For example, Thaler (1980) told subjects that they had been exposed to a rare fatal disease and that they now face a .001 chance of painless death within two weeks. They must decide how much they would be willing to pay for a vaccine, to be purchased immediately. The same subjects were also asked for the compensation they would demand to 
participate in a medical experiment in which they face a .001 chance of a quick and painless death. For most subjects the two prices differed by more than an order of magnitude.

A study by Viscusi, Magat and Huber (1987) documented a similar effect in a more realistic setting. Their respondents were recruited at a shopping mall and hardware store. The respondents were shown a can of fictitious insecticide, and were asked to examine it for their use. The current price of the can was said to be $\$ 10$. Respondents were informed that all insecticide can cause injuries if misused, including inhalation and skin poisoning (in households with young children, child poisoning replaced skin poisoning). The current risk level was said to be 15 injuries of each type per 10,000 bottles sold. Respondents were asked to state their willingness-to-pay (WTP) to eliminate or reduce the risks. In households without children, the mean WTP to eliminate both risks was $\$ 3.78$. The respondents were also asked to state the price reduction they would require to accept an increase of $1 / 10,000$ in each of the two risks. The results were dramatic: 77 percent of respondents in this condition said they would refuse to buy the product at any positive price.

The striking difference between WTA and WTP in these studies probably reflects the large difference in the responsibility costs associated with voluntary assumption of additional risk, in contrast to a mere failure to reduce or eliminate existing risk. The asymmetry between omission and commission is familiar in legal doctrine, and its impact on judgments of responsibility has been confirmed by psychological research (Ritov and Baron, forthcoming). The asymmetry affects both blame and regret after a mishap, and the anticipation of blame and regret, in turn, could affect behavior.

A moral attitude is involved in another situation where huge discrepancies between buying and selling prices have been observed, the evaluation of environmental amenities in cost benefit analyses. Suppose some corporation offers to buy the Grand Canyon and make it into a water park complete with the world's largest water slide. How do we know whether the benefits of this idea exceed its costs? As usual there are two ways to ask the question, depending on what is the status quo. If there is no theme park in the status quo, then people can be asked the minimum amount of money they would accept to agree to add one (WTA). Alternatively, if the corporation currently owns the right, people could be asked how much they would be willing to pay to buy it back and prevent the theme park from being built (WTP). Several surveys have been conducted where the researchers asked both types of questions for such things as clean air and well-maintained public parks. Most studies find that the WTA responses greatly exceed the WTP answers (Cummings, Brookshire, and Schulze, 1986). The difference in typical responses actually does not tell the entire story. As two close observers of this literature note (Mitchell and Carson, 1989, p. 34): "Studies using WTA questions have consistently received a large number of protest answers, such as 'I refuse to sell' or 'I want an extremely large or infinite amount of compensation for agreeing to this,' and have 
frequently experienced protest rates [outright refusals to answer the question] of 50 percent or more." These extreme responses reflect the feelings of outrage often seen when communities are faced with the prospect of accepting a new risk such as a nuclear power plant or waste disposal facility (Kunreuther, Easterling, Desvousges, and Slovic, forthcoming). Offers of compensation to proposed communities often do not help as they are typically perceived as bribes. ${ }^{4}$

\section{Judgments of Fairness and Justice}

An implication of the endowment effect is that people treat opportunity costs differently than "out-of-pocket" costs. Foregone gains are less painful than perceived losses. This perception is strongly manifested in people's judgments about fair behavior. Kahneman, Knetsch and Thaler (1986) present survey evidence supporting this proposition. Samples of the residents of Toronto and Vancouver were asked a series of questions over the telephone about whether they thought a particular economic action was "fair." In some cases, alternative versions of the same question were presented to different groups of respondents. For each question, respondents were asked to judge whether the action was completely fair, acceptable, somewhat unfair, or very unfair. In reporting the results the first two categories were combined and called "acceptable" and the last two combined and called "unfair." Perceptions of fairness strongly depended on whether the question was framed as a reduction in a gain or an actual loss. For example:

Question 1a. A shortage has developed for a popular model of automobile, and customers must now wait two months for delivery. A dealer has been selling these cars at list price. Now the dealer prices this model at $\$ 200$ above list price.

$$
N=130 \quad \text { Acceptable } 29 \text { percent } \quad \text { Unfair } 71 \text { percent }
$$

Question 1b. A shortage has developed for a popular model of automobile, and customers must now wait two months for delivery. A dealer has been selling these cars at a discount of $\$ 200$ below list price. Now the dealer sells this model only at list price.

$$
N=123 \quad \text { Acceptable } 58 \text { percent } \quad \text { Unfair } 42 \text { percent }
$$

\footnotetext{
${ }^{4}$ This is a situation in which people loudly say one thing and the theory asserts another. It is of interest that the practitioners of contingent valuation elected to listen to the theory, rather than to the respondents (Cummings, Brookshire and Schulze, 1986). The accepted procedure uses WTP questions to assess value even in a context of compensation, relying on the theoretical argument that WTP and WTA should not be far apart when income effects are small.
} 
Imposing a surcharge (which is likely to be judged a loss) is considered more unfair than eliminating a discount (a reduction of a gain). This distinction explains why firms that charge cash customers one price and credit card customers a higher price always refer to the cash price as a discount rather than to the credit card price as a surcharge (Thaler, 1980).

The different intensity of responses to losses and to foregone gains may help explain why it is easier to cut real wages during inflationary periods:

Question 2a. A company is making a small profit. It is located in a community experiencing a recession with substantial unemployment but no inflation. The company decides to decrease wages and salaries 7 percent this year.

$$
N=125 \quad \text { Acceptable } 37 \text { percent Unfair } 63 \text { percent }
$$

Question 2b. A company is making a small profit. It is located in a community experiencing a recession with substantial unemployment and inflation of 12 percent. The company decides to increase salaries only 5 percent this year.

$$
N=129 \quad \text { Acceptable } 78 \text { percent } \quad \text { Unfair } 22 \text { percent }
$$

In this case a 7 percent cut in real wages is judged reasonably fair when it is framed as a nominal wage increase, but quite unfair when it is posed as a nominal wage cut.

The attitudes of the lay public about fairness, which are represented in their answers to these fairness questions, also pervade the decisions made by judges in many fields of the law. Supreme Court Justice Oliver Wendell Holmes (1897) put the principle this way: “It is in the nature of a man's mind. A thing which you enjoyed and used as your own for a long time, whether property or opinion, takes root in your being and cannot be torn away without your resenting the act and trying to defend yourself, however you came by it. The law can ask no better justification than the deepest instincts of man."

Cohen and Knetsch (1990) showed that this principle, embodied in the old expression that "possession is nine tenths of the law," is reflected in many judicial opinions. For example, in tort law judges make the distinction between "loss by way of expenditure and failure to make gain." In one case, several bales fell from the defendant's truck and hit a utility pole, cutting off power to the plaintiff's plant. The plaintiff was able to recover wages paid to employees which were considered "positive outlays" but could not recover lost profits which were merely "negative losses consisting of a mere deprivation of an opportunity to earn an income" (p. 18). A similar distinction is made in contract law. A party that breaches a contract is more likely to be held to the original terms if the action is taken to make an unforeseen gain than if it is taken to avoid a loss. 


\section{Commentary}

It is in the nature of economic anomalies that they violate standard theory. The next question is what to do about it. In many cases there is no obvious way to amend the theory to fit the facts, either because too little is known, or because the changes would greatly increase the complexity of the theory and reduce its predictive yield. The anomalies that we have described under the labels of the endowment effect, the status quo bias and loss aversion may be an exceptional case, where the needed amendments in the theory are both obvious and tractable.

The amendments are not trivial: the important notion of a stable preference order must be abandoned in favor of a preference order that depends on the current reference level. A revised version of preference theory would assign a special role to the status quo, giving up some standard assumptions of stability, symmetry and reversibility which the data have shown to be false. But the task is manageable. The generalization of preference theory to indifference curves that are indexed to reference level is straightforward (Tversky and Kahneman, 1991). The factors that determine the reference point in the evaluations of outcomes are reasonably well understood: the role of the status quo, and of entitlements and expectations are sufficiently well established to allow these factors to be used in locating the relevant reference levels for particular analyses.

As Samuelson and Zeckhauser noted, rational models that ignore the status quo tend to predict "greater instability than is observed in the world" (p. 47). We have added the claim that models that ignore loss aversion predict more symmetry and reversibility than are observed in the world, ignoring potentially large differences in the magnitude of responses to gains and to losses. Responses to increases and to decreases in price, for example, might not always be mirror images of each other. The possibility of loss aversion effects suggests, more generally, that treatments of responses to changes in economic variables should routinely separate the cases of favorable and unfavorable changes. Introducing such distinctions could improve the precision of predictions at a tolerable price in increased complexity.

After more than a decade of research on this topic we have become convinced that the endowment effect, status quo bias, and the aversion to losses are both robust and important. Then again, we admit that the idea is now part of our endowment, and we are naturally keener to retain it than others might be to acquire it.

- The authors wish to acknowledge financial support from Fisheries and Oceans Canada, the Ontario Ministry of the Environment, the Russell Sage Foundation, and Concord Capital Management. 


\section{References}

Cohen, David, and Jack L. Knetsch "Judicial Choice and Disparities Between Measures of Economic Values," Simon Fraser University Working Paper, 1990.

Coursey, Don L., John L. Hovis, and William D. Schulze, "The Disparity Between Willingness to Accept and Willingness to Pay Measures of Value," The Quarterly Journal of Economics, 1987, 102, 679-90.

Cummings, Ronald G., David S. Brookshire, and William D. Schulze, eds., Valuing Environmental Goods. Totowa, $\mathrm{NJ}$ : Rowman and Allanheld, 1986.

Hartman, Raymond, Michael J. Doane, and Chi-Keung Woo, "Consumer Rationality and the Status Quo," Quarterly Journal of Economics, forthcoming.

Hershey, John, Eric Johnson, Jacqueline Meszaros, and Matthew Robinson, "What Is the Right to Sue Worth?" Wharton School, University of Pennsylvania, June 1990.

Holmes, Oliver Wendell, "The Path of the Law," Harvard Law Review, 1897, 10, 457-478.

Kahneman, Daniel, Jack L. Knetsch, and Richard Thaler, "Fairness As a Constraint on Profit Seeking: Entitlements in the Market," American Economic Review, 1986, 76, 728-41.

Kahneman, Daniel, Jack L. Knetsch, and Richard Thaler, "Experimental Tests of the Endowment Effect and the Coase Theorem," Journal of Political Economy, December 1990, 98, 1325-1348.

Kahneman, Daniel, and Amos Tversky, "Choices, Values and Frames," American Psychologist, April 1984, 39, 341-350.

Knetsch, Jack L., "The Endowment Effect and Evidence of Nonreversible Indifference Curves," American Economic Review, 1989, 79, 1277-1284.

Knetsch, Jack L., "Derived Indifference Curves," working paper, Simon Fraser University, 1990.

Knetsch, Jack L., and J. A. Sinden, "Willingness to Pay and Compensation De- manded: Experimental Evidence of an Unexpected Disparity in Measures of Value," Quarterly Journal of Economics, August 1984, 99, 507-521.

Knetsch, Jack L., and J. A. Sinden, "The Persistence of Evaluation Disparities," Quarterly Journal of Economics, 1987, 102, 691-695.

Knez, Peter, Vernon Smith, and Arlington W. Williams, "Individual Rationality, Market Rationality, and Value Estimation," American Economic Review, May 1985, 75, 397-402.

Kunreuther, Howard, Douglas Easterling, William Desvousges, and Paul Slovic, "Public Attitudes Toward Citing a High Level Nuclear Waste Depository in Nevada," Risk Analysis, forthcoming.

Lowenstein, George, and Daniel Kahneman, "Explaining the Endowment Effect," working paper, Department of Social and Decision Sciences, Carnegie Mellon University, 1991.

Mitchell, Robert C., and R. T. Carson, Using Surveys to Value Public Goods. Washington, D.C.: Resources for the Future, 1989.

Ritov, Rita, and Jonathan Baron, "Statusquo and Omission Biases," Journal of Risk and Uncertainty, forthcoming.

Samuelson, William, and Richard Zeckhauser, "Status Quo Bias in Decision Making," Journal of Risk and Uncertainty, 1988, 1, 7-59.

Thaler, Richard, "Toward a Positive Theory of Consumer Choice," Journal of Economic Behavior and Organization, 1980, 1, 39-60.

Tversky, Amos, and Daniel Kahneman, "Loss Aversion and Riskless Choice: A Reference Dependent Model," Quarterly Journal of Economics, 1991.

Viscusi, W. Kip, Wesley A. Magat, and Joel Huber, "An Investigation of the Rationality of Consumer Valuations of Multiple Health Risks," RAND Journal of Economics, 1987, 18, 465-79. 
http://www.jstor.org

\title{
LINKED CITATIONS
}

- Page 1 of 2 -

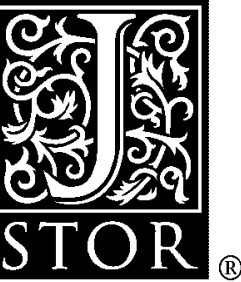

You have printed the following article:

\section{Anomalies: The Endowment Effect, Loss Aversion, and Status Quo Bias}

Daniel Kahneman; Jack L. Knetsch; Richard H. Thaler

The Journal of Economic Perspectives, Vol. 5, No. 1. (Winter, 1991), pp. 193-206.

Stable URL:

http://links.jstor.org/sici?sici=0895-3309\%28199124\%295\%3A1\%3C193\%3AATEELA\%3E2.0.CO\%3B2-V

This article references the following linked citations. If you are trying to access articles from an off-campus location, you may be required to first logon via your library web site to access JSTOR. Please visit your library's website or contact a librarian to learn about options for remote access to JSTOR.

\section{References}

The Disparity Between Willingness to Accept and Willingness to Pay Measures of Value

Don L. Coursey; John L. Hovis; William D. Schulze

The Quarterly Journal of Economics, Vol. 102, No. 3. (Aug., 1987), pp. 679-690.

Stable URL:

http://links.jstor.org/sici?sici=0033-5533\%28198708\%29102\%3A3\%3C679\%3ATDBWTA\%3E2.0.CO\%3B2-U

\section{Fairness as a Constraint on Profit Seeking: Entitlements in the Market}

Daniel Kahneman; Jack L. Knetsch; Richard Thaler

The American Economic Review, Vol. 76, No. 4. (Sep., 1986), pp. 728-741.

Stable URL:

http://links.jstor.org/sici?sici=0002-8282\%28198609\%2976\%3A4\%3C728\%3AFAACOP\%3E2.0.CO\%3B2-I

\section{Experimental Tests of the Endowment Effect and the Coase Theorem}

Daniel Kahneman; Jack L. Knetsch; Richard H. Thaler

The Journal of Political Economy, Vol. 98, No. 6. (Dec., 1990), pp. 1325-1348.

Stable URL:

http://links.jstor.org/sici?sici=0022-3808\%28199012\%2998\%3A6\%3C1325\%3AETOTEE\%3E2.0.CO\%3B2-W

\author{
The Endowment Effect and Evidence of Nonreversible Indifference Curves \\ Jack L. Knetsch \\ The American Economic Review, Vol. 79, No. 5. (Dec., 1989), pp. 1277-1284. \\ Stable URL: \\ http://links.jstor.org/sici?sici=0002-8282\%28198912\%2979\%3A5\%3C1277\%3ATEEAEO\%3E2.0.CO\%3B2-Y
}


http://www.jstor.org

\section{LINKED CITATIONS \\ - Page 2 of 2 -}

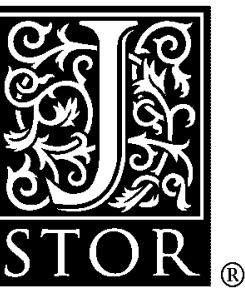

Willingness to Pay and Compensation Demanded: Experimental Evidence of an Unexpected Disparity in Measures of Value

Jack L. Knetsch; J. A. Sinden

The Quarterly Journal of Economics, Vol. 99, No. 3. (Aug., 1984), pp. 507-521.

Stable URL:

http://links.jstor.org/sici?sici=0033-5533\%28198408\%2999\%3A3\%3C507\%3AWTPACD\%3E2.0.CO\%3B2-7

\section{Individual Rationality, Market Rationality, and Value Estimation}

Peter Knez; Vernon L. Smith; Arlington W. Williams

The American Economic Review, Vol. 75, No. 2, Papers and Proceedings of the Ninety-Seventh Annual Meeting of the American Economic Association. (May, 1985), pp. 397-402.

Stable URL:

http://links.jstor.org/sici?sici=0002-8282\%28198505\%2975\%3A2\%3C397\%3AIRMRAV\%3E2.0.CO\%3B2-G

\section{Loss Aversion in Riskless Choice: A Reference-Dependent Model}

Amos Tversky; Daniel Kahneman

The Quarterly Journal of Economics, Vol. 106, No. 4. (Nov., 1991), pp. 1039-1061.

Stable URL:

http://links.jstor.org/sici?sici=0033-5533\%28199111\%29106\%3A4\%3C1039\%3ALAIRCA\%3E2.0.CO\%3B2-O

\section{An Investigation of the Rationality of Consumer Valuations of Multiple Health Risks}

W. Kip Viscusi; Wesley A. Magat; Joel Huber

The RAND Journal of Economics, Vol. 18, No. 4. (Winter, 1987), pp. 465-479.

Stable URL:

http://links.jstor.org/sici?sici=0741-6261\%28198724\%2918\%3A4\%3C465\%3AAIOTRO\%3E2.0.CO\%3B2-J 